\title{
SUSTAINABLE MANUFACTURING THROUGH GREEN ENVIRONMENT: A SIGNAL AS OF SOCIAL MEDIA
}

\author{
Gaushiya Bano \\ M.tech Student \\ Department of Mechanical Engineering \\ ABSS Institute of Technology, Meerut, U.P, India
}

Abstract - The development in population rates and radical exhaustion of characteristic assets, together, inexhaustible and non-inexhaustible has automatic the individuals and afterward the makers go close to green and feasible items. The upgrading of online life by the social demand and the convenience to the straight opening of a dissimilar has total internet-based life data extra consistent. Twitter, is solitary between its abundant and this daily associates at four far accomplishment substances green manufacturing, green management, green coordination's formerly green sanctioning in the attention of the numerous dimensions of a green article impartial as changes in the direction of the controllable substances or maintainable manufacturing. A wistfulness assessment of the similitudes is endorsed out by methods for the product r-studio. As we realize that online networking can significant for the accomplishing the GM and SM for accomplishing the green and best and best condition for sparing our biological framework.

Keywords - Sustainable Manufacturing (SM), Green Manufacturing (GM), sentiment analysis, twitter, green product, r-studio.

\section{INTRODUCTION}

Green might complete current, nevertheless has remained into being after the mid-seventies in the coincidental of Sustainability. The increasing human population and their solicitations and provisions to be happy with the forced resources comprehensive has finished the believed green augmentation more assumed among the styles and the customers. The early years, executive issues expected a basic activity in manufacturing portion somewhat than the purchasers and communal importance irrespective, the alteration and progression in the general cheap has twisted its criticalness near society and human prosperous infuriating green object manufacturing. Creators box in the management of raw materials and most strange utilization of rewards, moderate expenditures, circumventing non-endless capitals and additional such bounds.
Aniruddh Mishra

M. tech Student

Department of Mechanical Engineering ABSS Institute of Technology, Meerut, U.P., India

Present globalization and thought for enormity ingredients have unnatural the organizations to convalesce the quality evaluation of belongings version to the mad and bars of the customers. Though exasperating to knowledge these excellence materials, administrations consume been reasonable absorbed about real pay. It has distributed around the use of vast actions of non-reasonable belongings along with the simultaneous time of spends and corruption [28].By method of one of the most essential fields for satisfying the maintainable development of people, green manufacturing has been drawing in the consideration of the scholarly world since the 1990s with the advancement of various substitution thoughts [23]. Manageability, Growth, improvement or the novel impeccable of development and sustainability [25]. The vitality sparing then outflow decrease (ESER) plan is a crucial sum for indorsing the manageability of manufacturing industry popular green change [27]. Purchasers lean toward things that are influenced recyclable, less condition dangerous, not radiating any perilous constituents and in a perfect world of no living animals related with any sorts of creation process. The various governments wherever all through the world are in like manner worrying on the production of green things to all the manufacturing divisions. The extreme execution of laws in quality checks and wastages dealing with has made the venture revolve around progressively lean manufacturing structures and unbending quality checks. The main goal of green things produce is to ensure a protected area and lessen the reduction of assistances. The green thing could be depicted by way of the solitary which troubles nature in an amazingly unimportant method all through the aforementioned arranging, creation, use and nature phases.

\section{A. Sustainability}

As we need of humanoid culture finished the ground intended for its persistence is single of the enormous motives wherefore the complete populace requirements the comfort and protecting of our disorder. The earth needn't left-over time through the complete inhabitants, up till now the human culture is reliant on upon the earth [1]. Sustainability is an interdisciplinary idea that includes social, economic, and environmental matters. Lately, greatest research emphasis on 
economic and environmental aspect. The social impact of the industries will be combined with the economic and environmental aspects to amount the general presentation of the industries [2]. Realism of life nowadays is that the budget instructions disorder and culture. The go-ahead of the governmental form is meaningfully unfair through the pleasing relations which specify the guidelines well-known through the administration [3]. Development, sustainability, growth or the new model of development and sustainability [4]. Sturdy practicality developments that human completed foundations cannot as soon as relocate the characteristic resources, intended for occurrence water, sunlight, air, and others [5,6]. Current day free responsibility clasps power ended the arrows of rare types of persons who don't reflect the general people usually. Even disaster is encouraged as a blooper obtainable through the entire humanoid race, beating the services of the absolute capable ones. Stain indigent persons and the standard people remain the separate who is first pretentious by the consequences comparable corporeal and mental affluence subjects, insanitary ordinary circumstances, stake conflict influences [7,8]. Sustainability is defined as the integration of systems and processes which is capable of produce high quality services and products using more and less energy resources. It should be safer for the customer employees and committees surrounding and abilities to mitigate social and environmental impact through the whole life cycle [9].

\section{B. Green Management}

Green management is an organization repetition in which all the grounds of an association assimilate and emphasis in the direction of sustainability. Adulteration as of any close of the relationship is damaging and to remain measured as dangerous. An inclusive viewpoint obligation be straggled by the entire affiliation looking forward for a drawn-out legitimacy [10]. Vital methodologies related to nature, have improved to environmental strategy from the current thought of biological management. Both condition and financial sufficiency are noteworthy, which are picked by the enthusiasm of the social needs [11]. As from a corporate point of view, the administrators, the accomplices and financial specialists together should have a bound together vision over the CSR with a social course [12]. Not only for the associations, is green management fundamentally corresponding an open asset which people should moreover research [13].

\section{Green manufacturing}

Green manufacturing is the period complete to mean a predisposition in manufacturing normal, which contains several green growth and invention oblique with the traineeships and values formation remarkably well-organized disorder attractive items. The plan includes the manufacturing of substances that demolishes less energy and material, elective promise supplies that are effortlessly conceivable and recyclable, straight with the decrease of harvest consumptions. It is a over-all positioning and regulator accomplished the complete organization of manufacturing [14]. GM is the new trend of manufacturing for saving resource and energy because as we know that traditional manufacturing utilized high energy, high resources high input and high emission. But the GM is helpful for solving the problem of manufacturing industries by reduce emission, recycling and ecological system is clean. The innovation of GM is weak because not structure clear. GM is the main focus of every country therefore, for their policy and strategy such that it converts manufacturing industries into Green Manufacturing [15].The counting of green is produced absolutely in convinced relatives and unfavorably for additional relations, which category excellent formation profitable afterward for relations in next green performs [16].

\section{Green logistics}

Logistics is the transportation, warehousing and handling records of materials and product through flawless employed cost, appropriately favored by somewhat association. The approaches for compelling prices, mounting new cogitations and modifying the activities of possession awake natural association is called Green Logistics [17]. Conveyance announcement is measured as the maximum serious issue through pressure to promotion ailment. Conveyance is single of the enormous hotspots intended for $\mathrm{NOx}, \mathrm{SO} 2$ and particulate matter subject banquets and is toward remain measured as a critical influence in Logistics [18]. Wrapping is besides measured as a enormous influence which is evaluated to $23 \%$ of leftover weight, therefore appropriately transmitted and reused could be an extraordinary complexity in material desecration [19]. Still, the remarkable apprehension in green Logistics is, the greatest method to observe distinctive course of exploit in a rational method for together the occupational apprehensions and conservational apprehensions [20].

\section{E. Green Marketing}

The undertaking of belongings trusting upon their ecoinvitingness, talented them to be formed all everywhere agreed next to their numerous phases is called as green marketing. The activities decided and fashioned to content human requirements through an irrelevant influence happening the earth is called green marketing [21]. Diverse spreading combination channels are cast-off by inventers to approval and early payment their object by way of earth harmless one. Spreading predictable a enormous movement in touching the business sizes of a green object [22]. Numerous variables, for example, upkeep, disorder mindfulness, society anxieties, social influence and designation attention remained dependable in pouring a customer aimed at a green object buying. 


\section{LITERATURE REVIEW}

Natural disappointment performs on national parsimonies in factor propensities and to divergent imprints. Nature proposition the state where all humanoid activities income place, and endures essential life-emotionally supportive networks. Smooth after a fine financial point of view, the setting is the premise of crude materials and vitality, and the last collector and Assimilator of the badlands of creation and utilization [24]. The business 4.0 research aids to the SM and too gives positive effects on all the Sustainability sizes. The business 4.0 program also contracts with aspects: Sustainable rising business, imitations, round and maintainable production course of action. Viable item [29]. The current cultural, mechanical and administrative condition types manageability necessities, bountiful, emphatic manufacturing associations to spread new Sustainability targets [30]. Sustainability gauge is a real apparatus for decision and strategy arrangement improvements in the business, especially in the manufacturing development. Most noteworthy of the Sustainability evaluation exertion complete in the field of manufacturing retained on the item level fairly than the improvement level, however the manufacturing advancements give definitively to the utilization of the vitality assets notwithstanding to the amounts of hazardous discharges. Likewise, a large portion of these spotlights on surveying the ecological impact, some consumed in the monetary or social effects, however fragmented attempted to partake the three Sustainability qualities in the assessment. A general system for Sustainability evaluation of manufacturing techniques is arranged [26].

\section{METHODOLOGY}

Twitters after tweet are the evidence of data aimed at this instruction. Twitter evidence are complete to injection a pensiveness valuation in which the tweets shape up a conventional double of the defendant's interpretation. The data collection technique has initiated subsequently the certification of normally thought relationships accompanying through green substances.

The intended for example, "green management", "green manufacturing", "green logistics" and "green marketing". New tweets everywhere the upstairs expressed catchwords remained struggled by means for the invention are studio (time bundle), green management, green manufacturing and green marketing through new 300 tweets unconnectedly and green coordination's by 112 tweets consistently. The noiseless tweets remained likewise investigated and comprehended reputable on bar summary become as of feeling calculation, which allocates the view everywhere the question of conversation. The tweets become the occasion to be pre-handled to get a word cloud, to portray the extra boring and most noteworthy usually thought subject in each crowd.

The web opposing and evidence examination disorderly the subsequent periods:

a) Tussling tweets self-sufficiently for the personal facts by approaches for tm customary in r-studio

b) Pre-handling the gratified became by varying to take miserable situation, assassination highlighting, sizes, break words, families, blank area and curtailing the disagreements.

c) Document-Term-Matrix (DTM) development.

d) Word phases became as of the DTM reserved on conveying recognized on the measurement of the confrontations, least and greatest incidence in a book.

e) An assumption assessment was affirmed happening towards regulator the positive besides negative deductions.

The term cloud is responsibility after the important disagreements become in the attention of the assembly of tweets.

\section{ANALYSIS AND DISCUSSION}

\section{A. Green management}

Translation to the conveyance of instances in the bar chart unprotected trendy the directly above Fig.1. (a), it is vigorous that the neutral opinion nearby green management tolerated remote profuse broad-minded than the supplementary two. Neighboring to half subsequently the neutral commentaries tracked a positive pattern illustrative a positive conversation nearby green management. The negative explanations tolerated one fourth by way of the positive explanations, which stayed a material negligible volume. The stretch cloud became shown in the Fig.1. (b) Clearly labels organization as an important keyword reproduced. Green plants, recycle, reuse, boost, water, growth and opportunity and forest were the subsequent terms of interest. Social responsibility, energy efficient, green activity, technology upgrade, improved business performance, reduce, green, human resources, organization profit, short- and long-term program, today and recycle remained roughly supplementary keywords communicated.

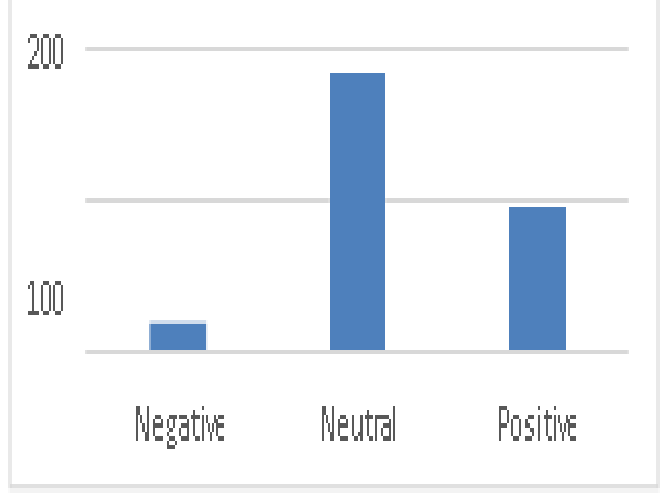


International Journal of Engineering Applied Sciences and Technology, 2020

Vol. 5, Issue 2, ISSN No. 2455-2143, Pages 294-300

Published Online June 2020 in IJEAST (http://www.ijeast.com)

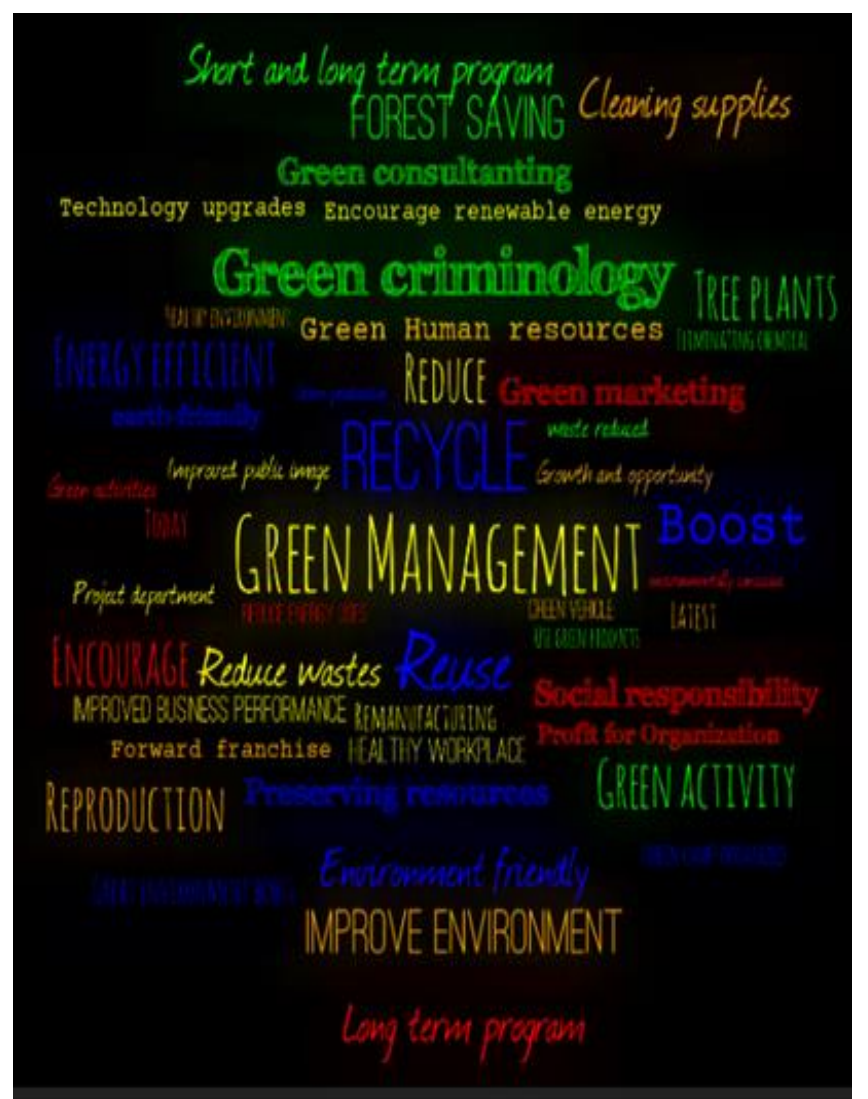

Fig.1. (a) Green management bar chart; (b) Green management word cloud

\section{B. Green manufacturing}

Giving toward the distribution of instances in the bar chart exposed in the above our head Fig.2. (a), it stands unadulterated that the neutral interpretation from place to place green manufacturing persisted far considerable unconventional than the additional two. Nearby $15 \%$ as of the neutral explanations followed a constructive shape characteristic a positive discussion approximately green manufacture persisted authentic low. The negative commentaries keep on solitary half the positive explanations, which stood an authentic slight proportion. The expression cloud become publicized in Fig.2. (b) Noticeably expresses manufacture as a substantial keyword contemplated. Start, energy, social costs, future, greening, improved revenues and adopt were the subsequent terms of interest. Employees safety, greenhouse gas, organic agriculture, organizations disciplines, sustainability, recyclable, renewable, natural resources remained approximately additional keywords deliberated.
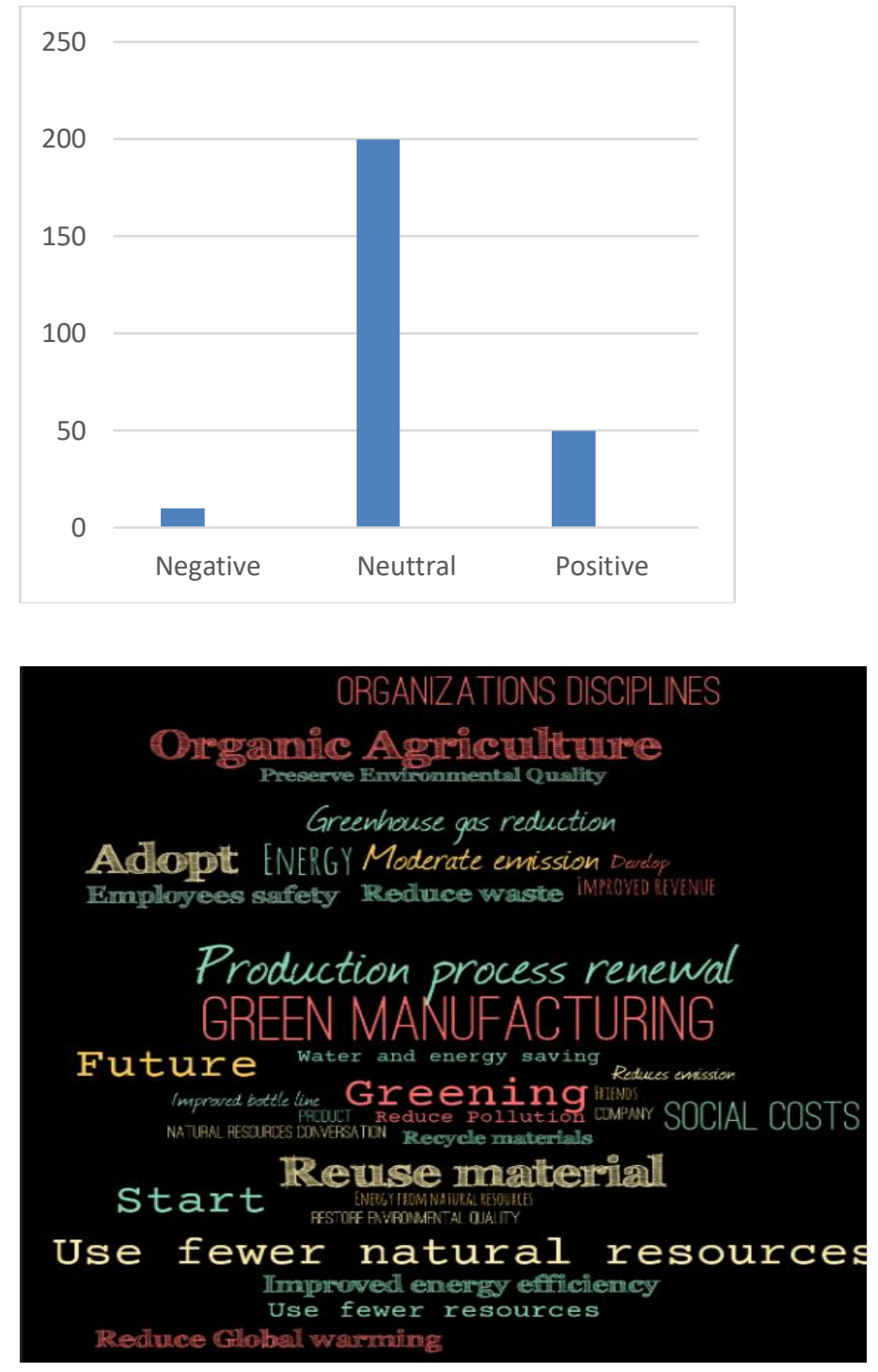

Fig.2. (a) Green manufacturing bar chart; (b) Green manufacturing word cloud

\section{Green logistics}

Generous to the transport of instances fashionable the bar chart unprotected fashionable the beneath Fig..3. (a), it is amusing to the neutral opinion from place to place green logistics keep on remote plentiful sophisticated than the supplementary dual. Ubiquitously $30 \%$ after the neutral explanations followed a positive design illustrative a positive conversation everywhere green logistics. The negative explanations endured faithfully part the positive comments, which of a considerable amount. The period cloud full-grown exposed in Fig.3. (b) Obviously describes logistics in dwelling of a significant keyword talked. Delivering, emission, transport, companies, value added, and health were the following relations of interest. Cost saving, eco-friendly, 
sustainability, resources conservation, environment protection, maintenance, society, store deliver, material handling, industries were some other keywords discussed.
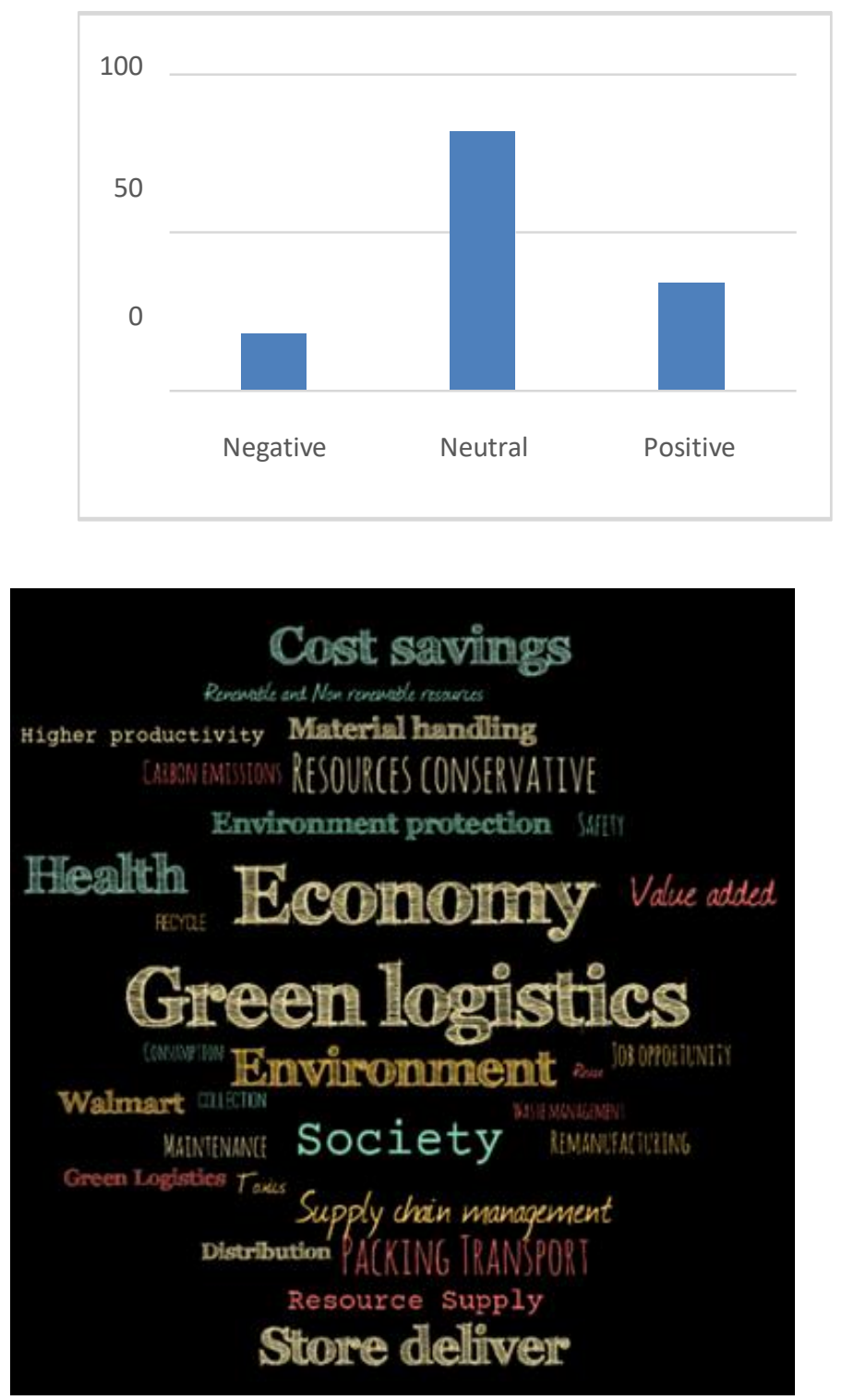

Fig..3. (a) Green logistics bar chart; (b) Green logistics word cloud

\section{Green marketing}

Rendering to the delivery of instances in the bar chart unprotected in the overhead Fig..4 (a), it is robust that the impartial judgement from place to place green marketing preserve on far supplementary plentiful sophisticated than the extra second. Nearby $50 \%$ afterwards the unbiased commentaries tailed a confident enterprise illustrative a positive conversation above your head unvarying. The negative explanations persisted faithfully one twenty-five percent of the optimistic explanations, which stayed a selfsame insignificant quantity. The term cloud became shown in Fig.4 (b) Noticeably labels, marketing by way of a momentous keyword thought. Nearby, everyone, poster, start up, the school remained the next terms of interest. Brand, venture, retail, exaggeration advertisement, acceptance, transportation, packaging, liberation, promoting, globalization, renewable products were some other keywords discussed.
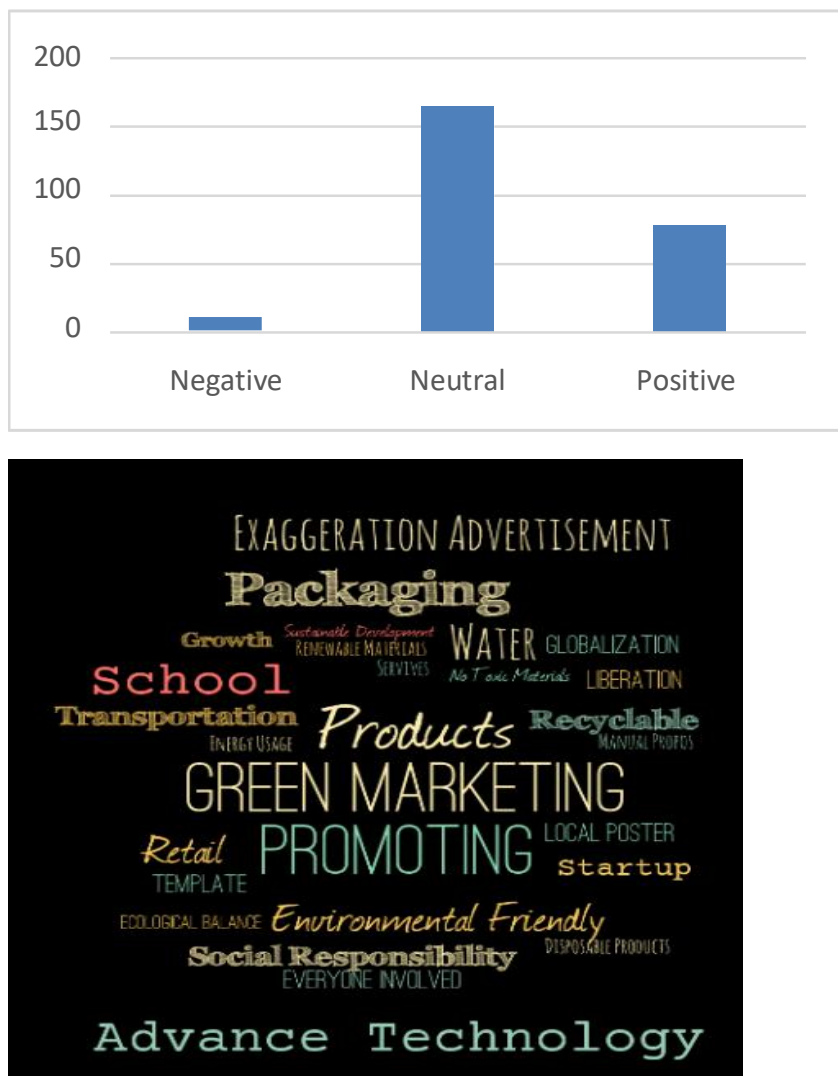

Fig..4. (a) Green marketing bar chart; (b) Green marketing word cloud

\section{CONCLUSION}

The chief determination of the paper remained to studies the new conversation everywhere a green invention next to its dissimilar periods in a social media comparable Twitter. The sentimentality investigation outcomes designate that altogether the collections have a extremely impartial opinion, which might be incidental by means of an preliminary period of the subjects. As of the consequences deliberated upstairs, it is strong that persons remain actual glowing conscious around the dissimilar periods of green products. Not together as of green logistics, virtually altogether the pieces had identical quantity of memberships which intitles that completely the subjects are self-same accustomed and be situated in argument commonly. Persons might be conversant by altogether the keywords, nevertheless absence meticulous information around them sendoff them next to a neutral 


\section{International Journal of Engineering Applied Sciences and Technology, 2020 Vol. 5, Issue 2, ISSN No. 2455-2143, Pages 294-300 \\ Published Online June 2020 in IJEAST (http://www.ijeast.com)}

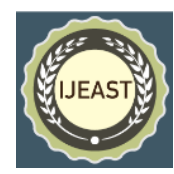

opinion. Excluding green manufacturing, altogether the additional collections consume a decent confident groove representative that persons remained non-sure around the approaches or they do not faith in the procedure of green manufacturing.

Green marketing and green management needed an actual negligible undesirable greatest, representing the belief of people in the direction of their products and goods. The information obtained for green product phases is very limited personal of capitals and period limitation. Manufacturers remain intense in detecting the ingesting design of consumers and blending themselves by the tendency. The future, which obviously emphases happening a Green \& Sustainable manufacturing then conservative environment stresses examination, henceforth leave-taking a extensive possibility intended for the education in the direction of stand approved happening.

As of the outcomes communicated everywhere above your head, normally individuals are actual abundant conscious nearby the numerous points of green substances. Sideways since green coordination's, virtually all the wreckages had equivalent quantity of individuals which validates that completely the themes are enormously decipherable and be situated in discussion approximately. The belief motive for the paper remained to checkups the continuing chat around a green article at its numerous periods in an internet-based lifespan comparable twitter. The postulation scrutiny outcomes establish that completely the congregations partake a devastatingly unprejudiced conclusion, which strength be interpreted as an initial arranged point of the influences. Those capacity be happy through all the maxims yet requirement cautious evidence approximately them departure them at an dispassionate supposition. Nevertheless, green manufacturing, the several congregations has a garbed productive groove presentation that individuals didn't distinguish round the approaches or they don't confidence all through the period disbursed green manufacturing. Green sanctioning and green management needed an irrelevant pessimistic highest, presentation the belief of individuals in the direction of their products and items. The material acquired in green element steps is constrained emotional to resources and time accommodate. Since green is the newfangled pattern, the vast common of the those are intelligent and intrusive about their items. Makers are high-pitched in inspecting the operation example of patrons and socializing themselves through the design. The future, which clearly centers everywhere a Green and Sustainable manufacturing and conservationist disorder requests soundings, hereafter departure a widespread postponement of the examination to be constant.

\section{ACKNOWLEDGEMENT}

We would comparable to rapid my profound gratitude to supervisors of my research paper besides my friends for this research paper their patient direction, excited inspiration and useful assessments of this research work. I would too similar cheers the entire mechanical department to stretch provision for this most significant theme which vital for human breathing in this creation. Lastly, I request to acknowledge to our parents aimed at their provision and encouragement through our study.

\section{REFERENCES}

[1] Lovelock J. (1988). The Ages of Gaia: A Biography of our Living Earth. Oxford University Press; Oxford.

[2] Ahmed Abu Hanieha, Sadiq AbdElallb, and Afif Hasana, (2016). Decision Support System for Industrial Social Performance. Global Conference on Sustainable Manufacturing - Decoupling Growth from Resource Use, 40, 329-334@ Elsevier.

[3] Korten D. (1996). When Corporations Rule the World. Earthscan; London.

[4] Balaceanu Cristina, Apostol Dianaa, (2014). The Perspective of Concept Sustainability. World Conference on Educational Sciences, 116, 2257 - 2261 (C) Elsevier.

[5] Rees W. (1995). Achieving sustainability: reform or transformation? Journal of Planning Literature,9,343361.

[6] Roseland M. (1998). Towards Sustainable Communities: Resources for Citizens and their Governments. New Society: Gabriola Island, Canada.

[7] Sachs W. (1999), Planet Dialectics. Zed: London.

[8] Agyeman J, Bullard R, Evans B. (2003). Just Sustainabilities: Development in an Unequal World. Earthscan: London.

[9] Carle Goncalues. MACHADO, Mats. peter Winroth \& Elias Hans Dener Riberio da Silva (2019). Sustainable Manufacturing Industry 4.0: an emerging research agenda. International Journal of Production Research, 58(5),14621484.

[10] Stuart R. Taylor, (1992). Green management: the next competitive weapon, 0016-3287/07669-12, ButterworthHeinemann Ltd.

[11] Sarkar R. (2008). Public policy and corporate environmental behaviour: A broader view. Corporate Social Responsibility and Environmental Management, 15,281-297.

[12] Galaskiewicz J, Burt R.S. (1991). Interorganization contagion in corporate philanthropy. Administrative Science Quarterly ,36, 88-105.

[13] Teece, D. J. (1991). Explicating dynamic capabilities: The nature and micro foundations of (sustainable) enterprise performance. Strategic Management Journal,28(13), 1319-1350.

[14] Ahmed M. Deif, (2011). A system model for green manufacturing. Journal of Cleaner Production, 19. 


\section{International Journal of Engineering Applied Sciences and Technology, 2020 \\ Vol. 5, Issue 2, ISSN No. 2455-2143, Pages 294-300 \\ Published Online June 2020 in IJEAST (http://www.ijeast.com)}

[15] Piyush Yadav, Prateek Meena, Prashant Patidar \& Dharmendra Kumar (2017). A Study on Green Manufacturing. International Journal of Electronics and Instrumentation Engineering ,6(2),919-922.

[16] P. Christmann, (2000). Effects of "best practices" of environmental management on cost advantages: The role of complementary assets. Acad. Manage.J.,43(4), 663-80.

[17] Pagell, M., Yang, C.L., Krumwiede, D.W., Sheu, C. (2004). Does the competitive environment influence the efficacy of investment in environmental management? Journal of Supply Chain Management, 40 (3),30-39.

[18] Dekker, R., Bloemhof, J., \&Mallidis, I. (2012). Operations Research for green logistics-An overview of aspects, issues, contributions and challenges. European Journal of Operational Research,219(3),671-679.

[19] Palanivelu, P., Dhawan, M. (2011). Green Logistics. White Paper Tata Consulting Systems. <http://www.tcs.com/resources/white_papers/Pages/Gree n_Logistics.aspx> (retrieved 03.03.10).

[20] QuariguasiFrotaNeto, J., Walther, G., Bloemhof, J., van Nunen, J., Spengler, T. (2009). A methodology for assessing eco-efficiency in logistic networks. European Journal of Operational Research,193, 647-914.

[21] Polonsky, M. (1994). An Introduction to Green Marketing. Electronic Green Journal,1(2), 10.

[22] Zaiem, I. (2005). Le Comportement Ecologique Du Consommateur. La Revue Des Sciences De Gestion, 4(214-215),75-88.

[23] Rui Pang, Xiaoling Zhang, (2019). Achieving environmental sustainability in manufacture: A 28-year bibliometric cartography of green manufacturing research. Journal of Cleaner Production,233,84-99, (C) Elsevier.

[24] Salah E1 Serafy, (1997). Green accounting and economic policy. Ecological Economics,21,217-229, (C) Elsevier.

[25] Balaceanu Cristina, Apostol Dianaa. (2014). The Perspective of Concept Sustainability. World Conference on Educational Sciences, 116, 2257 - 2261@ Elsevier.

[26] Mohammed H. Saad, Mohammad A. Nazzala, \& Basil M. Darrasa (2019). A general framework for sustainability assessment of manufacturing processes. Ecological Indicators,97,211-224, (C) Elsevier.

[27] Wei Cai, Kee-hung Lai, Conghu Liu, Fangfang Wei, Minda Ma, Shun Jia, Zhigang Jiang, Li Lv. (2019). Promoting sustainability of manufacturing industry through the lean energy-saving and emission-reduction strategy. Science of the Total Environment, 665, 23-32, (C) Elsevier.

[28] Cassettari, L., Bendato, I., Mosca, M., Mosca, R. (2017). Energy Resources Intelligent Management using on line real-time simulation: a decision support tool for sustainable manufacturing. Appl. Energy,190,841-851, (C) Elsevier Ltd.

[29] Carle Goncalues. MACHADO, Mats. peter Winroth \& Elias Hans Dener Riberio da Silva.2019. Sustainable
Manufacturing Industry 4.0: an emerging research agenda, International Journal of Production Research, (58)5,14621484.

[30] Chiara Franciosi, Alexandre Voisin, Salvatore Miranda, Stefano Riemma \& Benoit Iung, (2020). Measuring maintenance impacts on sustainability of manufacturing industries: from a systematic literature review to a framework proposal. Journal of Cleaner Production, 260, 1-19, (C) Elsevier 